\title{
An Easily Synthesized Covalent Nanocage that Hosts Fullerenes in Multiple Charge States and Selectively Binds $\mathbf{C}_{\mathbf{7 0}}$
}

\author{
Daniel A. Rothschild, Aaron Tran, William P. Kopcha, Jianyuan Zhang, and Mark C. Lipke*
}

[a] D. A. Rothschild, A. Tran, W. P. Kopcha, Dr. J. Zhang, Dr. M. C. Lipke Department of Chemistry and Chemical Biology

Rutgers, The State University of New Jersey

123 Bevier Rd, Piscataway, NJ 08854 (USA)

E-mail: ml1353@chem.rutgers.edu

Abstract: Discrete nanocages provide a way to solubilize, separate, and tune the properties of molecular guests, including fullerenes and other aromatics. However, few such nanocages can be synthesized efficiently from inexpensive starting materials, limiting their practical utility. To address this limitation, we developed a new pyridiniumlinked cofacial porphyrin nanocage $\left(\mathrm{Cage}^{4+}\right)$ that can be prepared efficiently on a gram scale. NMR studies in $\mathrm{CD}_{3} \mathrm{CN}$ reveal that Cage ${ }^{4+}$ binds $\mathrm{C}_{60}$ and $\mathrm{C}_{70}$ with association constants $>10^{8} \mathrm{M}^{-1}$ and complete selectivity for extracting $\mathrm{C}_{70}$ from mixtures of both fullerenes. The solubility of $\mathrm{Cage}^{4_{+}}$in polar solvents enabled electrochemical characterization of the host-guest complexes $\mathbf{C}_{60} @$ Cage $^{4+}$ and $\mathbf{C}_{70} @ \mathrm{Cage}^{4+}$, finding that the redox properties of the encapsulated fullerenes are minimally affected despite the positive charge of the host. Complexes of the -1 and -2 charge states of the fullerenes bound in $\mathrm{Cage}^{4+}$ were subsequently characterized by UV-vis-NIR and NMR spectroscopies. The relatively easy preparation of $\mathrm{Cage}^{4+}$ and its ability to bind fullerenes without substantially affecting their redox properties suggests that $\mathbf{C}_{60} @ \mathbf{C a g e}^{4+}$ and $\mathbf{C}_{70} @ \mathbf{C a g e}^{4+}$ may be directly useful as solubilized fullerene derivatives.

\section{Introduction}

Macrocycles and nanocages with aromatic walls are popular synthetic targets for their interesting structures and ability to host aromatic guests. ${ }^{1}$ Many such molecular receptors have been examined for use in separating, ${ }^{2}$ sensing, ${ }^{3}$ or tuning the electronics ${ }^{4}$ and/or reactivity ${ }^{5}$ of various aromatic species. Fullerenes are one notable class of aromatic guests owing to their useful electron-accepting properties ${ }^{6}$ and the challenges that exist in purifying, ${ }^{2 a, 7}$ solubilizing, ${ }^{8}$ and derivatizing ${ }^{9}$ these aromatic carbon allotropes-challenges which might be overcome using the host-guest chemistry of suitable receptors. Nanocages with large aromatic components (e.g., porphyrins, ${ }^{2 \mathrm{f}, 2 \mathrm{~d}, 4 \mathrm{a}, 10}$ naphthalene or perylene diimides, ${ }^{8 a, 11}$ pyrenes $^{12}$, anthracenes ${ }^{13}$, etc. $\left.{ }^{14}\right)$ often show particularly high affinities for binding fullerenes due to the large $\pi-\pi$ overlap provided upon complexation. However, the synthesis of such hosts is typically challenging or costly, either

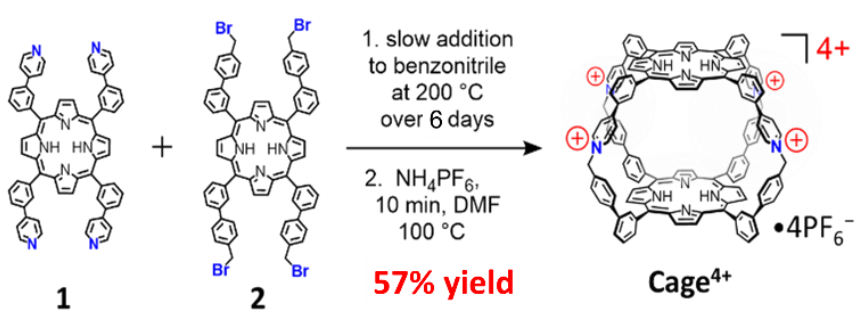

Scheme 1. Synthesis of Cage ${ }^{4+}$.

relying on the stochiometric use of precious metals to link the aromatic walls ${ }^{15}$ or utilizing covalent linkages ${ }^{16}$ that result in low yields and challenging purifications. Furthermore, the individual components of these hosts often require numerous steps to synthesize ${ }^{17}$ compounding the inefficiency of cage formation.

To overcome these limitations, we sought to develop an easily synthesized porphyrin nanocage of the appropriate shape and rigidity to bind fullerenes with high affinities and selectivity. Herein, we report the synthesis, characterization, and fullerenebinding properties of a tetracationic bis-porphyrin nanocage, Cage $^{4+}$, which was prepared in good yield on a gram scale by the formation of pyridinium linkages between complementary pyridyland benzylbromide- substituted porphyrins (Scheme 1). This cage uptakes $\mathrm{C}_{60}$ and $\mathrm{C}_{70}$ quantitatively in $\mathrm{MeCN}$, with essentially complete selectivity for extracting $\mathrm{C}_{70}$ from mixtures containing both fullerenes. Usefully, the solubility of Cage ${ }^{4+}$ in polar solvents enabled electrochemical characterization of the bound fullerenes, showing their electronic properties are minimally perturbed by encapsulation. The scalable synthesis of $\mathrm{Cage}^{4+}$, its strong binding of fullerenes, and the preserved electronics of fullerene guests suggest that $\mathbf{C}_{60} @$ Cage $^{4+}$ and $\mathbf{C}_{70} @$ Cage $^{4+}$ might be directly useful as solubilized fullerene derivatives.

\section{Results and Discussion}

Synthesis of $\mathrm{Cage}^{4+}$. As shown in Scheme 1, Cage ${ }^{4+}$ was prepared via simple $S_{N} 2$ reactions between complementary 4 -fold symmetric pyridyl- and benzylbromide- substituted porphyrins 1 and 2. Since the resulting pyridinium linkages are assumed to form irreversibly, efficient synthesis of the cage was achieved 
using pseudo-high-dilution conditions in which the two components were added slowly to a moderate volume of $\mathrm{PhCN}$ at $200{ }^{\circ} \mathrm{C}$ over 6 days. The initial product Cage $4 \mathrm{Br}$ is insoluble in $\mathrm{PhCN}$ and DMF, allowing oligomeric byproducts to be removed by washing with DMF. Heating the remaining solid in a DMF solution of $\mathrm{NH}_{4} \mathrm{PF}_{6}$ provided the salt Cage $\cdot 4 \mathrm{PF}_{6}$ as the only soluble product in a yield of up to $57 \%$. The identity of Cage ${ }^{4+}$ was confirmed by a variety of NMR techniques $\left({ }^{1} \mathrm{H},{ }^{13} \mathrm{C}\left\{{ }^{1} \mathrm{H}\right\}\right.$, and

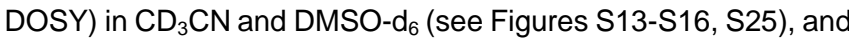
also by $\mathrm{ESI}(+)$-HRMS characterization (Figures S33-36).

Notably, the precursor components of $\mathbf{C a g e}^{4+}$ were also prepared easily in only a few steps from inexpensive starting materials (Scheme 2), suggesting the synthesis of Cage ${ }^{4+}$ could be economically scaled. Confirming this possibility, we prepared $>1 \mathrm{~g}$ of $\mathrm{Cage} 4 \mathrm{PF}_{6}$ in a single batch, with the yield (40\%) suffering only a little from scale up. For comparison, we surveyed over 35 reported 3D fullerene receptors, ${ }^{18}$ finding that most were prepared on scales of $<100 \mathrm{mg}$, with the largest synthesis providing only $200 \mathrm{mg}$ of the cage, ${ }^{11 \mathrm{c}}$ likely reflecting the cost and/or synthetic inefficiency of preparing such structures. To our knowledge, Cage ${ }^{4+}$ is the only fullerene-binding nanocage for which a gram scale synthesis has been demonstrated.

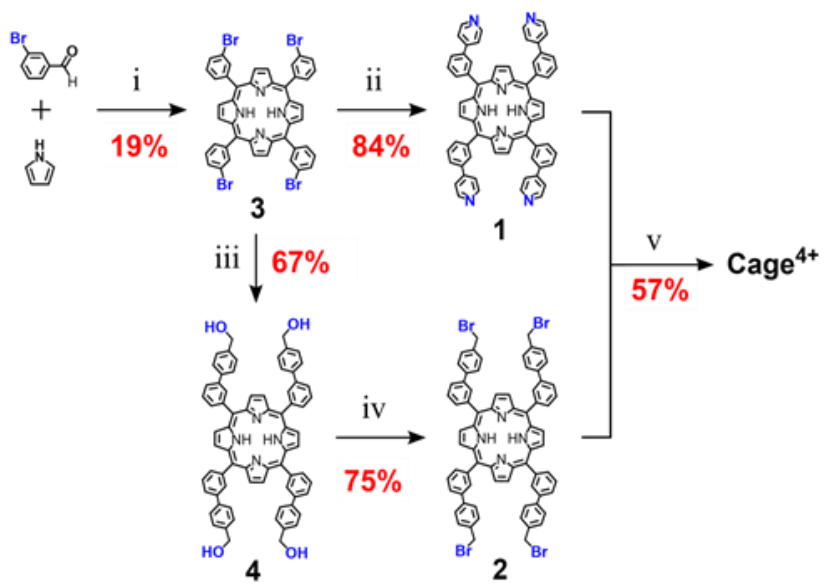

Scheme 2. Full synthetic scheme for preparation of Cage $^{4+}$. (i) $160{ }^{\circ} \mathrm{C}, 2 \mathrm{~h}$, propionic acid (ii) 20 equiv 4-pyridylboronic acid, 20 equiv $\mathrm{K}_{2} \mathrm{CO}_{3}, 12 \mathrm{~mol} \%$ dppfPdCl $2,110{ }^{\circ} \mathrm{C}, 72 \mathrm{~h}, 20: 80$ water/toluene, (iii) 20 equiv 4-(hydroxymethyl)phenylboronic acid, 20 equiv $\mathrm{K}_{2} \mathrm{CO}_{3}, 12 \mathrm{~mol} \%$ (dppf) $\mathrm{PdCl}_{2}, 110^{\circ} \mathrm{C}, 72 \mathrm{~h}, 20 / 80$ water/toluene, (iv) 12 equiv $\mathrm{PBr}_{3}, 16 \mathrm{~h}, 0$ to $25^{\circ} \mathrm{C}, \mathrm{CH}_{2} \mathrm{Cl}_{2}$. (v) $200^{\circ} \mathrm{C}, 6$ days, $\mathrm{PhCN}$, followed by excess $\mathrm{NH}_{4} \mathrm{PF}_{6}, 100^{\circ} \mathrm{C}, 10 \mathrm{~min}$, DMF.

Association of fullerenes in Cage $^{4+}$. Host-guest complexes of $\mathrm{C}_{60}$ and $\mathrm{C}_{70}$ in Cage $^{4+}$ were formed after $3 \mathrm{~h}$ of sonicating suspensions of the fullerenes in $\mathrm{CD}_{3} \mathrm{CN}$ solutions of the host. Encapsulation was evident from changes to all the ${ }^{1} \mathrm{H}$ NMR resonances of $\mathrm{Cage}^{4+}$ upon formation of $\mathbf{C}_{60} @ \mathrm{Cage}^{4+}$ and $\mathbf{C}_{70} @ \mathrm{Cage}^{4+}$ (Figure 1), with the upfield porphyrin $\mathrm{NH}$ signals of the host providing particularly useful NMR handles for tracking complexation. The ${ }^{13} \mathrm{C}\left\{{ }^{1} \mathrm{H}\right\}$ NMR spectra of the host-guest complexes confirm the encapsulation of the fullerenes. Most notably, a large signal at $140.15 \mathrm{ppm}$ was observed for the $\mathrm{C}_{60}$ guest in $\mathbf{C}_{60} @$ Cage $^{4+}$ (Figure S20), and five resonances arising from encapsulated $\mathrm{C}_{70}$ were observed for $\mathbf{C}_{70} @$ Cage $^{4+}$ (Figure

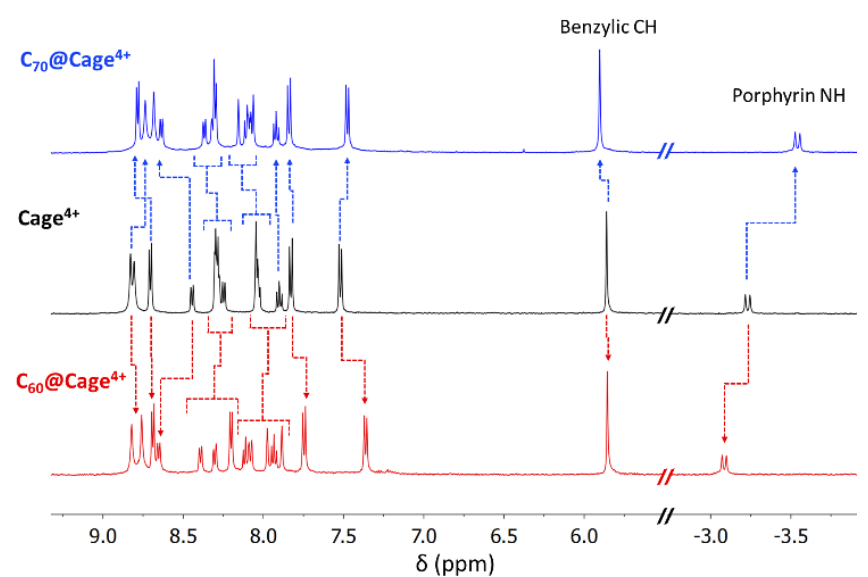

Figure 1: Partial ${ }^{1} \mathrm{H}$ NMR spectra of $\mathbf{C a g e}^{4+}$ (black), $\mathbf{C}_{60} @$ Cage $^{4+}$ (red), and $\mathrm{C}_{70} @ \mathrm{Cage}^{4+}$ (blue) in $\mathrm{CD}_{3} \mathrm{CN}(500 \mathrm{MHz}, 298 \mathrm{~K})$. Changes to resonances of $\mathrm{Cage}^{4+}$ upon guest uptake are labelled with dotted arrows.

S24), whereas ${ }^{13} \mathrm{C}$ NMR signals of $\mathrm{C}_{60}$ and $\mathrm{C}_{70}$ cannot otherwise be observed in $\mathrm{CD}_{3} \mathrm{CN}$ due to the negligible solubility of these fullerenes in this solvent. ${ }^{19} \mathrm{ESI}(+)$-HRMS characterization further confirmed the identity of the host-guest complexes, showing a series of peaks with the expected isotope patterns for $\mathbf{C}_{60} @ C$ age ${ }^{4+}$ and $\mathbf{C}_{70} @ C_{a g e}{ }^{4+}$ with 0 to 2 PF $_{6}{ }^{-}$anions associated (Figure S37-S44).

The strength of association between $\mathrm{C}_{60}$ and Cage $^{4+}$ was estimated based on the observation that the empty host could not be detected by ${ }^{1} \mathrm{H}$ NMR spectroscopy after sonicating an excess of the fullerene in a saturated $(0.65 \mathrm{mM})$ solution of $\mathrm{Cage}^{4+}$ in $\mathrm{CD}_{3} \mathrm{CN}$ (Figure 1). Using the reported solubility of $\mathrm{C}_{60}$ in $\mathrm{MeCN}$ $(0.56 \mu \mathrm{M})^{18}$ and the lower limit of ${ }^{1} \mathrm{H}$ NMR detection we determined for Cage $^{4+}(1.94 \mu \mathrm{M})$, it can be concluded that $\mathbf{C}_{60} @$ Cage $^{4+}$ has a very large association constant of $\geq 6.0 \times 10^{8}$ $\mathrm{M}^{-1}$. Strong binding of $\mathrm{C}_{70}$ was similarly evident from the complete disappearance of the ${ }^{1} \mathrm{H}$ NMR signals of empty Cage ${ }^{4+}$ after sonication in the presence of this fullerene (Figure 1), but the binding constant could not be quantified because the solubility of $\mathrm{C}_{70}$ in acetonitrile does not appear to be established in the literature. Competition experiments did, however, reveal that $\mathrm{C}_{70}$ binds much more favorably than $\mathrm{C}_{60}$ in $\mathrm{Cage}^{4+}$. Sonication of a 10:1 mixture of $\mathrm{C}_{60}: \mathrm{C}_{70}$ in a solution of $\mathrm{Cage}^{4+}$ led to complete disappearance of the signals of the free host from the ${ }^{1} \mathrm{H}$ NMR spectrum after $3 \mathrm{~h}$, initially providing $\mathbf{C}_{60} @ \mathrm{Cage}^{4+}$ and $\mathbf{C}_{70} @$ Cage $^{4+}$ in similar amounts (see Figure S30). However, the ratio of $\mathbf{C}_{70} @$ Cage $^{4+}$ to $\mathbf{C}_{60} @ \mathbf{C a g e}^{4+}$ steadily increased upon further sonication, until only the $\mathrm{C}_{70}$ complex could be observed by ${ }^{1} \mathrm{H}$ NMR spectroscopy after $26 \mathrm{~h}$ (Figure S30). These, observations show that the kinetics of fullerene uptake are similar for both guests, but $\mathbf{C}_{70} @$ Cage $^{4+}$ is the thermodynamically more favorable complex. Thus, $\mathrm{Cage}^{4+}$ is highly effective for separating $\mathrm{C}_{70}$ from mixtures of $\mathrm{C}_{60}$ and $\mathrm{C}_{70}$, showing perfect selectivity within the limits of ${ }^{1} \mathrm{H}$ NMR detection ( $\geq 30$-fold selectivity for $\mathrm{C}_{70}$ ).

Structural analysis of host-guest complexes. Crystals suitable for single-crystal XRD analysis could not be obtained for $\mathrm{Cage}^{4+}$ or its host-guest complexes, ${ }^{20}$ so DFT structural optimizations were performed. The optimized structure of Cage ${ }^{4+}$ 
(Figure 2A) has a coplanar arrangement of its porphyrin faces, with a centroid-to-centroid separation of $11.9 \AA$. A distance of 20.5 $\AA$ was found between the benzylic carbon atoms at opposite ends of the cage. The dimensions of the host were altered only slightly in the optimized structure of $\mathbf{C}_{70} @$ Cage $^{4+}$ (Figure 2C); spacing between the porphyrin faces is expanded to $12.2 \AA$ and the distance between the benzylic carbon atoms is contracted to 20.2 $\AA$. In contrast, the spacing of the porphyrin faces is expanded much more (to 13.4 $\AA$ ) in the optimized structure of $\mathbf{C}_{60} @ \mathbf{C a g e}^{4+}$ (Figure $2 \mathrm{~B}$ ), and the benzylic carbon atom spacing is contracted considerably (to $19.0 \AA$ ). Thus, the geometry of Cage ${ }^{4+}$ is well suited to hosting $\mathrm{C}_{70}$, while considerable distortion is needed to host $\mathrm{C}_{60}$. These results provide an explanation for the experimentally observed preference for binding $C_{70}$ vs. $C_{60}$, especially since Cage ${ }^{4+}$ consists primarily of $\mathrm{sp}^{2}$ to $\mathrm{sp}^{2}$ linkages that are not expected to provide much conformational flexibility.
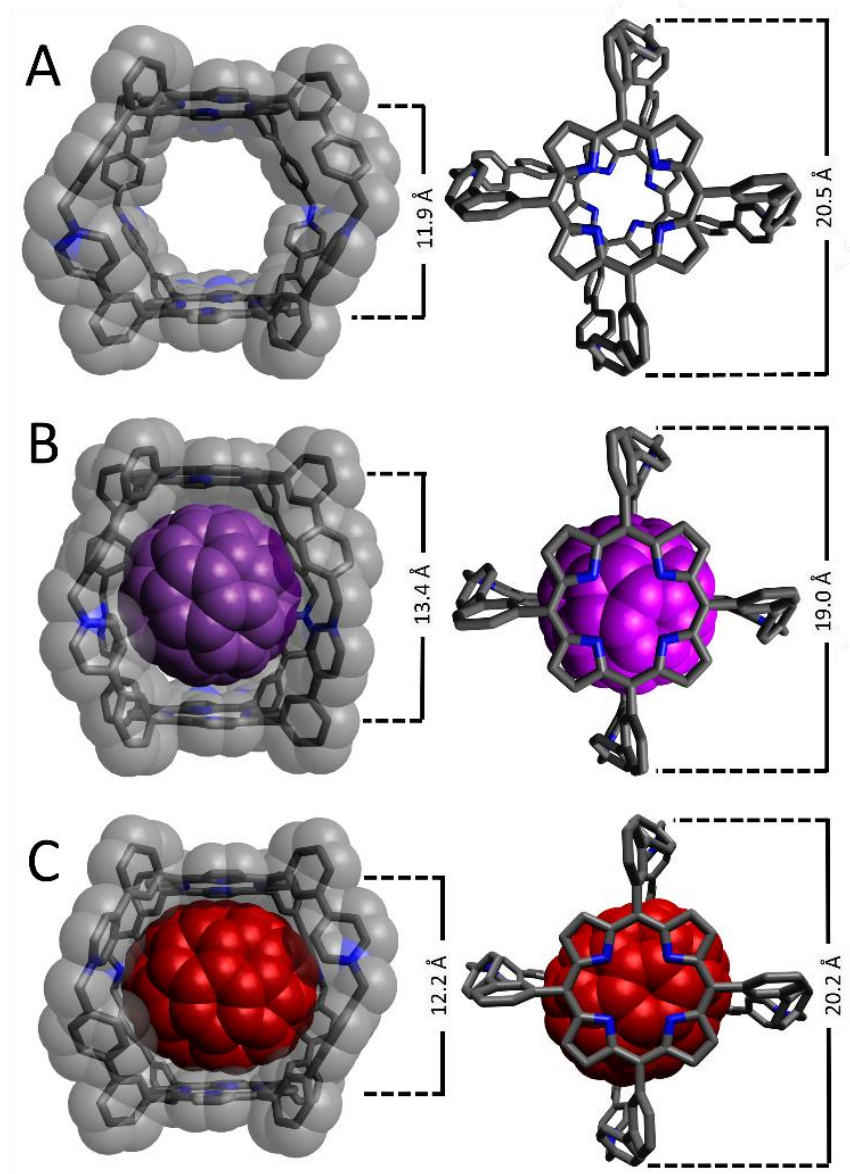

Figure 2: DFT optimized structures of (A) $\mathrm{Cage}^{4+}(B 3 L Y P / 6-31+G(d, p))$, (B) $\mathrm{C}_{60} @ \mathrm{Cage}^{4+}(\mathrm{B} 3 L Y P / 3-21+G)$, and (C) $\mathbf{C}_{70} @$ Cage $^{4+}(B 3 L Y P / 3-21+G)$. All optimizations were performed using an SMD solvation model for acetonitrile.

The dimensions of $\mathrm{Cage}^{4+}$ and its fullerene complexes were evaluated experimentally using DOSY NMR spectroscopy (Figure S25-S27). A diffusion coefficient $(D)$ of $8.76 \times 10^{-11} \mathrm{~m}^{2} / \mathrm{s}$ was determined for Cage $^{4+}$ in dmso- $d_{6}$, corresponding to an effective hydrodynamic radius ${ }^{21}(r)$ of $1.25 \mathrm{~nm}$, which matches well with the van der Waals distance (ca. $2.5 \mathrm{~nm})^{22}$ across the widest dimension of the computationally optimized structure (Figure $2 A$ ). A similar diffusion constant was measured for $\mathbf{C}_{60} @$ Cage $^{4+}(D=$ $8.34 \times 10^{-11} \mathrm{~m}^{2} / \mathrm{s} ; r=1.31 \mathrm{~nm}$, Figure S26), while $\mathbf{C}_{70} @ \mathrm{Cage}^{4+}$ diffuses more slowly $\left(D=7.01 \times 10^{-11} \mathrm{~m}^{2} / \mathrm{s} ; r=1.56 \mathrm{~nm}\right.$, Figure S27) even though the optimized structures of the host-guest complexes suggest that the latter exhibits less structural distortion relative to the empty host. The disparity of the diffusion coefficient of $\mathbf{C}_{70} @ \mathrm{Cage}^{4+}$ relative to the empty host may reflect altered interactions with other solutes, such as the $\mathrm{PF}_{6}{ }^{-}$counteranions. The influence of anions on the diffusion of the nanocage was assessed by comparing the diffusion of $\mathrm{Cage}^{4+}$ as its $\mathrm{PF}_{6}^{-}, \mathrm{BF}_{4}^{-}$ and $\mathrm{BPh}_{4}{ }^{-}$salts. The $\mathrm{BF}_{4}{ }^{-}$counteranions increase the rate of diffusion of Cage $^{4+}$ substantially $\left(D=1.14 \times 10^{-10} \mathrm{~m}^{2} / \mathrm{s}\right.$, Figure S29), while $\mathrm{BPh}_{4}^{-}$anions result in $\mathrm{Cage}^{4+}$ diffusing only slightly faster $\left(D=9.46 \times 10^{-11} \mathrm{~m}^{2} / \mathrm{s}\right.$, Figure S28) than observed for its $\mathrm{PF}_{6}{ }^{-}$salt. Since counteranions influence the diffusion of $\mathrm{Cage}^{4+}$, we speculate that the different diffusion rates for the host-guest complexes arise from the $\mathrm{C}_{60}$ vs. $\mathrm{C}_{70}$ guests having differing influences on the association of the cage with its $\mathrm{PF}_{6}$ counteranions.

Travelling-wave ion-mobility spectrometry (TWIMS) was employed as an additional technique to compare the effective sizes-specifically the collisional cross sections-of Cage ${ }^{4+}$ and its complexes with fullerene guests. ${ }^{23}$ Conveniently, this gasphase technique allows for selective measurement of the 4+ ions of the cage and host-guest complexes to eliminate any complicating influences of counteranions. Under optimized conditions, Cage $^{4+}$ had a drift time of 23.99 ms, while the same experimental parameters provided slightly longer drift times of $25.62 \mathrm{~ms}$ and $26.01 \mathrm{~ms}$ for $\mathbf{C}_{60} @ \mathbf{C a g e}^{4_{+}}$and $\mathbf{C}_{70} @ \mathrm{Cage}^{4_{+}}$, respectively (Figure S45). Thus, the host-guest complexes have very similar effective cross sections, while the empty host appears slightly smaller, which is consistent with TWIMS measurements reported for other cationic hosts that encapsulate fullerenes. ${ }^{23 a}$

Electrochemical Characterization. The electronaccepting properties of fullerenes are important to many of their possible applications, so cyclic voltammetry was used to determined how encapsulation by $\mathrm{Cage}^{4+}$ affects the redox properties of $\mathrm{C}_{60}$ and $\mathrm{C}_{70}$ (Figure 3 and Table 1). The empty host Cage $^{4+}$ exhibits reversible reductions at $-1.51 \mathrm{~V}$ and $-1.92 \mathrm{~V}$ vs. $\mathrm{FC}^{+/ 0}$ in DMF (Figure 3A). By comparison with monomeric porphyrins representing each half of $\mathrm{Cage}^{4+}$ (Figure S46, S47), the first reduction of the cage was assigned to the reduction of both porphyrin faces and the four pyridinium groups, while the smaller, more negative reduction feature of the cage corresponds to the second reduction of each of its porphyrin rings. Thus, reductions of the cage correspond to a $6 \mathrm{e}^{-}$process followed by a $2 \mathrm{e}^{-}$process, though the measured currents are closer to a 2:1 ratio. ${ }^{24}$ Deviation from ideal behavior is unsurprising considering that anions affect diffusion rates of $\mathrm{Cage}^{4+}$ (see above). It is likely that interactions between $\mathrm{Cage}^{4+}$ and anions are altered considerably as the cage is reduced, which would affect its diffusion rate, and in turn, the observed peak currents for subsequent reductions.

The host-guest complexes $\mathbf{C}_{60} @$ Cage $^{4+}$ and $\mathbf{C}_{70} @$ Cage $^{4+}$ both show four additional reversible or quasireversible redox couples that can be attributed to the fullerene guests (Figures $3 B, C)$. Despite the $4+$ charge of the host, the first reductions observed for the encapsulated fullerenes occur at potentials $\left(E_{1 / 2}\right.$ $=-0.82 \mathrm{~V}, \mathbf{C}_{60} @ \mathrm{Cage}^{4+} ;-0.78 \mathrm{~V}, \mathbf{C}_{70} @ \mathrm{Cage}^{{ }^{4+}}$ ) that are close to those of the one electron reductions of free $\mathrm{C}_{60}(-0.82 \mathrm{~V})^{25}$ and free $\mathrm{C}_{70}(-0.80 \mathrm{~V})^{26}$ in DMF (Table 1). ${ }^{27}$ Even more surprisingly, the second reductions of the fullerene guests are shifted 


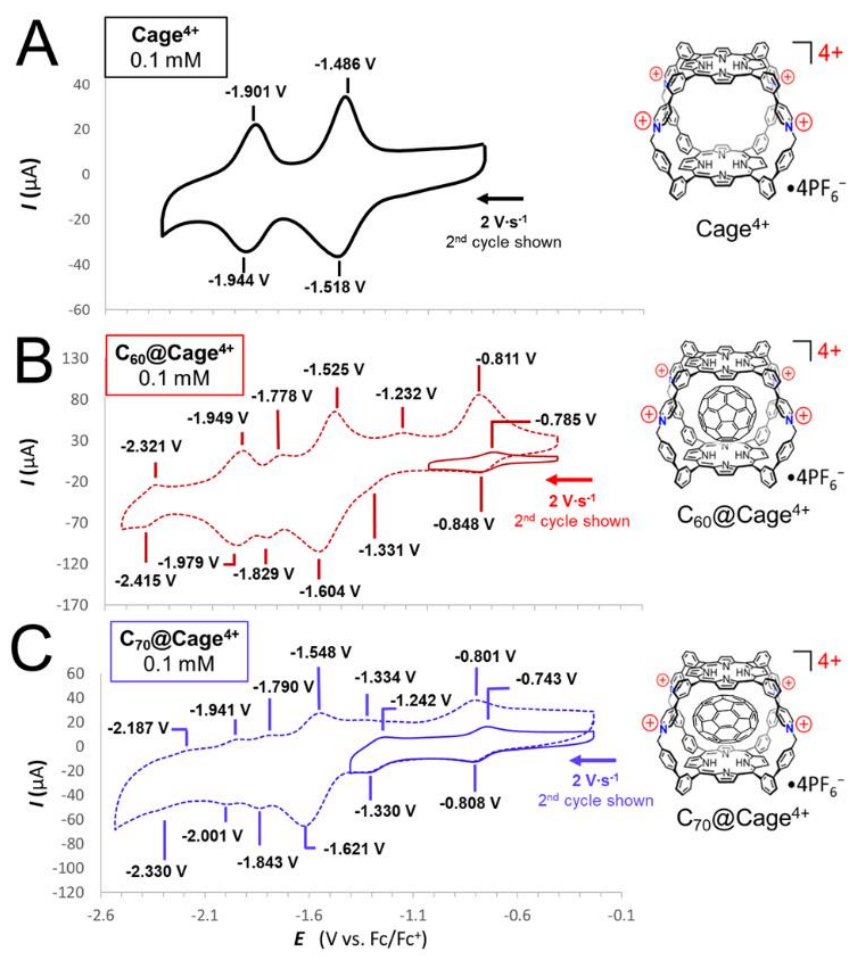

Figure 3: Cyclic voltammograms recorded in DMF with $0.1 \mathrm{M}\left[\mathrm{Bu}_{4} \mathrm{~N}\right]\left[\mathrm{PF}_{6}\right]$ supporting electrolyte and (A) $0.1 \mathrm{mM} \mathrm{Cage}^{4+}$ at a scan rate of $2 \mathrm{~V} \mathrm{~s}^{-1}$; (B) 0.1 mM C60@Cage ${ }^{4+}$ at a scan rate of $2 \mathrm{~V} \mathrm{~s}^{-1}$; and (C) $0.1 \mathrm{mM} \mathrm{C}_{70} @ \mathrm{Cage}^{4+}$ at a scan rate of $2 \mathrm{~V} \mathrm{~s}^{-1}$.

Table 1: Comparison of the reduction potentials ${ }^{a}$ of $\mathrm{C}_{60}, \mathrm{C}_{70}, \mathrm{Cage}^{4+}$ $\mathrm{C}_{60} @ \mathrm{Cage}^{4+}$, and $\mathrm{C}_{70} @ \mathrm{Cage}^{4+}$.

\begin{tabular}{|c|c|c|c|c|c|c|}
\hline & $\begin{array}{c}\text { 1st } C_{n} \\
\text { Reduction }\end{array}$ & $\begin{array}{c}2^{\text {nd }} C_{n} \\
\text { Reduction }\end{array}$ & $\begin{array}{l}{ }^{1 \text { st }} \text { Cage } \\
\text { Reduction }\end{array}$ & $\begin{array}{l}3^{\text {rd }} C_{n} \\
\text { Reduction }\end{array}$ & $\begin{array}{l}2^{\text {nd }} \text { Cage } \\
\text { Reduction }\end{array}$ & $\begin{array}{c}4^{\text {th }} C_{n} \\
\text { Reduction }\end{array}$ \\
\hline $\mathrm{C}_{60^{\circ}}$ & $-0.82 \mathrm{~V}$ & $-1.23 \mathrm{~V}$ & - & $-1.82 \mathrm{~V}$ & - & $-2.36 \mathrm{~V}$ \\
\hline $\mathrm{C}_{70}$ & $-0.80 \mathrm{~V}$ & $-1.22 \mathrm{~V}$ & - & $-1.74 \mathrm{~V}$ & - & $-2.25 \mathrm{~V}$ \\
\hline $\mathrm{C}_{60} @$ Cage $^{4+}$ & $-0.82 \mathrm{~V}$ & $-1.33 \mathrm{~V}^{\mathrm{c}}$ & $-1.56 \mathrm{~V}$ & $-1.80 \mathrm{~V}$ & $-1.96 \mathrm{~V}$ & $-2.37 \mathrm{~V}$ \\
\hline $\mathrm{C}_{70} @$ Cage $^{4+}$ & $-0.78 \mathrm{~V}$ & $-1.29 \mathrm{~V}$ & $-1.58 \mathrm{~V}$ & $-1.82 \mathrm{~V}$ & $-1.97 \mathrm{~V}$ & $-2.26 \mathrm{~V}$ \\
\hline Cage $^{4+}$ & - & - & $-1.50 \mathrm{~V}$ & - & $-1.92 \mathrm{~V}$ & - \\
\hline
\end{tabular}

[a] Unless otherwise noted, listed potentials refer to $E_{1 / 2}$ values relative to $\mathrm{Fc}^{+/ 0}$ for reversible redox couples measured in DMF containing $0.1 \mathrm{mM}$ analyte and $0.1 \mathrm{M} \mathrm{TBAPF}_{6}$ as a supporting electrolyte. [b] Reduction potentials of $\mathrm{C}_{60}$ are taken from ref. 77. [c] $E_{\mathrm{pc}}$ value for a reduction of the $\mathrm{C}_{60}$ guest that overlaps with a reduction of the host.

cathodically relative to the second reductions of the free fullerenes. The second reduction of $\mathbf{C}_{70} @ \mathbf{C a g e}^{4+}\left(E_{1 / 2}=-1.29 \mathrm{~V}\right)$ is about $70 \mathrm{mV}$ negative of the free $\mathrm{C}_{70}{ }^{-} / \mathrm{C}_{70^{2-}}$ redox couple $\left(E_{1 / 2}\right.$ $=-1.22 \mathrm{~V}$ ), while the second fullerene reduction in $\mathbf{C}_{60} @ \mathbf{C a g e}^{4+}$ overlaps partially with reductions of the host, representing about a $100 \mathrm{mV}$ cathodic shift relative to free $\mathrm{C}_{60}{ }^{-} / \mathrm{C}_{60}{ }^{2-}$. This counterintuitive behavior might be explained by close association of anions with the host-guest complexes, which could mitigate the electrostatic influence of the cationic host. Regardless of the cause, it is notable that the redox properties of $\mathrm{C}_{60}$ and $\mathrm{C}_{70}$ are not affected much by association in $\mathrm{Cage}^{4+}$ since other cationic hosts substantially alter the redox properties of fullerene guests. ${ }^{4 a, c, d}$ Likewise, solubilizing fullerenes by covalent functionalization also substantially alters their redox properties. ${ }^{28}$ Since the inherent electron-accepting capabilities of fullerenes are well studied for a variety of possible applications, ${ }^{6,29}$ it will likely be useful that Cage $^{4+}$ can solubilize these carbon allotropes without significantly perturbing their established redox properties.

Scanning to more negative potentials in the CVs reveals that the electrostatic influence of the reduced fullerenes shifts the first reductions of the host to potentials that are 50 to $70 \mathrm{mV}$ negative of the corresponding reductions of empty Cage $^{4+}$ (Table 1). However, the next cage-centered reductions are altered by a smaller amount, appearing only $20-40 \mathrm{mV}$ negative of the second reduction of the empty host despite the fullerene guests accepting an additional electron between the first and second reductions of the host. It is conceivable that electrostatic repulsion between the host and guests in their more reduced states (i.e., when both are in anionic states) triggers the expulsion of the fullerene anions, such that reduction processes corresponding to the empty host and free guest are observed at more negative potentials. Consistent with this possibility, the most negative observable reductions of the fullerene guests appear at nearly the same potentials as the corresponding reductions of the free fullerenes. Additionally, some of the reoxidation waves for the fullerenes (e.g., the $\mathrm{C}_{60}{ }^{-}$to $\mathrm{C}_{60}$ oxidation) are shifted somewhat in CVs that scan a large potential window vs. those scanning just the first two fullerene reductions (Figure 3B,C). Such behavior is consistent with the possibility of fullerene ejection occurring in more reduced states, resulting in reoxidation processes corresponding to the free fullerenes.

Binding Studies of $\mathbf{C}_{60}{ }^{n-}(\mathbf{n}=1,2)$. Since CV data suggest that fullerides may be ejected from the cage in some oxidation states of the host and guests, we sought to confirm that Cage ${ }^{4+}$ can bind the first two reduced states of the fullerenes. The association of $\mathrm{C}_{60}{ }^{-}$and $\mathrm{C}_{60}{ }^{2-}$ in $\mathrm{Cage}^{4+}$ was examined via titration experiments monitored by ${ }^{1} \mathrm{H}$ NMR spectroscopy. A solution of $\left[\mathrm{Cp}_{2}{ }_{2} \mathrm{Co}\right]\left[\mathrm{C}_{60}\right]$ in DMF was titrated in 0.1 equiv increments into a solution of $\mathrm{Cage}^{4+}$ in $\mathrm{CD}_{3} \mathrm{CN}$, resulting in the appearance of a new benzylic $\mathrm{CH}$ signal at $5.6 \mathrm{ppm}$ for the host-guest complex $\mathbf{C}_{60}{ }^{-} @$ Cage $^{4+}$. This new benzylic $\mathrm{CH}$ signal was observed as distinct from that of the empty host, which decreased steadily as $\mathrm{C}_{60}{ }^{-}$was added (Figures 4 and S31). Similar results were obtained upon titration of the host with $\mathrm{C}_{60}{ }^{2-}$ (Figure S32). Integration of the benzylic $\mathrm{CH}$ resonances of empty $\mathrm{Cage}^{4+}$ vs. those of $\mathbf{C}_{60}{ }^{-} @ \mathbf{C a g e}^{4+}$ and $\mathbf{C}_{60}{ }^{2-} @ \mathbf{C a g e}{ }^{4+}$ provided lower-limit

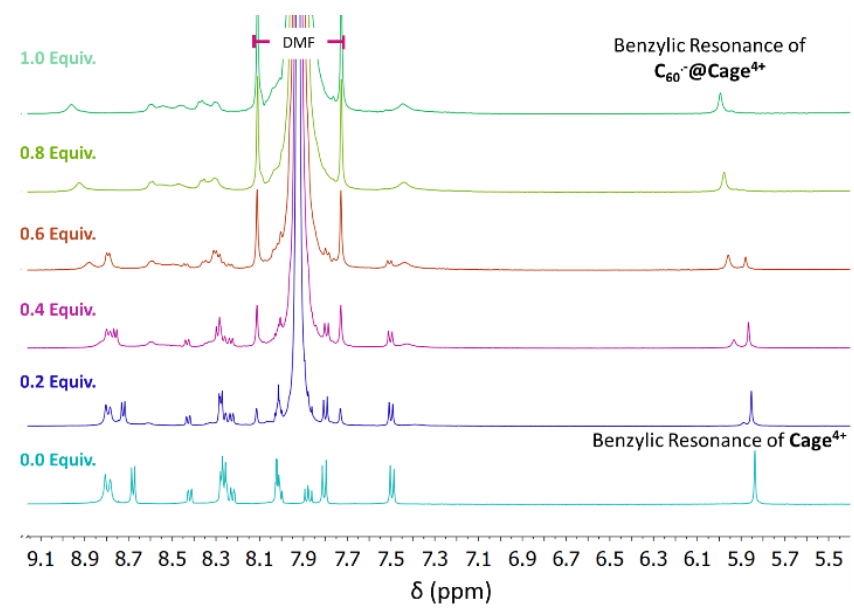

Figure 4. Changes to the ${ }^{1} \mathrm{H}$ NMR spectra of a solution of Cage $4 \mathrm{PF}_{6}$ in $\mathrm{CD}_{3} \mathrm{CN}$ in response to titration with a solution of $\left[\mathrm{Cp}^{*}{ }_{2} \mathrm{Co}\right]\left[\mathrm{C}_{60}\right]$ in DMF. Broad new signals are observed corresponding to the host-guest complex $\mathbf{C}_{60}{ }^{-} @ \mathbf{C a g e}^{4+}$ formed upon association of paramagnetic $\mathrm{C}_{60}{ }^{-}$in $\mathrm{Cage}^{4+}$. 
estimates of the association constants of $10^{7} \mathrm{M}^{-1}$ and $10^{5} \mathrm{M}^{-1}$, respectively. However, it is likely that these values substantially underestimate the strength of association since broadening of the resonances of the host-guest complexes and reduced solubility of the host-guest complexes relative to the empty host made it difficult to accurately quantify the concentrations of $\mathbf{C}_{60}{ }^{-} @ \mathbf{C a g e}^{4+}$ and $\mathbf{C}_{60}{ }^{2-} @$ Cage $^{4+}$. For comparison, the CV data of $\mathbf{C}_{60} @ \mathbf{C a g e}^{4+}$ was analyzed to determine the relative association constants for $\mathbf{C}_{60} @ \mathrm{Cage}^{4+}, \mathbf{C}_{60}{ }^{-} @ \mathrm{Cage}^{4+}$, and $\mathbf{C}_{60}{ }^{2-} @ \mathrm{Cage}^{4+}$ in DMF. Since encapsulation does not alter the first fullerene reduction potential, $\mathbf{C}_{60}{ }^{-} @$ Cage $^{4+}$ must have the same association constant as $\mathbf{C}_{60} @ \mathrm{Cage}^{4+}$, while the more negative $\mathbf{C}_{60}{ }^{-} / \mathbf{C}_{60}{ }^{2-}$ redox couple upon encapsulation suggests that binding of $\mathbf{C}_{60}{ }^{2-}$ is $1-2$ orders of magnitude weaker. These relative association constants are, thus, consistent with the pattern of association constants estimated by ${ }^{1} \mathrm{H}$ NMR spectroscopy in $\mathrm{CD}_{3} \mathrm{CN}$.

UV-vis-NIR Spectroscopy of Cage ${ }^{4+}$ and its Host-Guest Complexes with Fullerenes and Fullerides. The UV-vis spectrum of $\mathrm{Cage}^{4+}$ in DMF displays one Soret band and one set of Q-peaks, suggesting the two distinct porphyrin faces of the cage are electronically similar, as is consistent with their overlapping redox features observed by cyclic voltammetry. Reduction of the cage with decamethylcobaltocene $\left(\mathrm{Cp}^{*} \mathrm{Co}\right)$ causes the appearance of low-energy (>650 nm) absorbances that are characteristic of porphyrin radical anions (Figure S56). ${ }^{30}$ The intensity of these bands increases steadily with the addition of up to 4 equiv $\mathrm{Cp}^{*}{ }_{2} \mathrm{Co}$, and then less dramatically up to 6 equiv, which is consistent with nearly equal distribution of reduction over the two porphyrin faces and four pyridinium groups until all six sites are fully reduced. Addition of two more equivalents of $\mathrm{Cp}_{2}{ }_{2} \mathrm{Co}$ causes the low-energy bands to increase again, indicating further reduction of the porphyrins to their dianionic states (Figure S56). These results support the interpretation of the CV data described above for $\mathrm{Cage}^{4+}$, which is also consistent with DFT results indicating that the eight lowest unoccupied orbitals of the cage are centered on either the porphyrin faces or the pyridinium groups (Figure S65).

Since the first two fullerene reductions occur positive of the first reductions of $\mathrm{Cage}^{4+}$, it was possible to spectroscopically observe host-guest complexes of the singly and double reduced fullerenes in the 4+ charged host. The complex $\mathbf{C}_{60} @$ Cage $^{4+}$ was reduced via two sequential 1 equiv additions of $\mathrm{Cp}_{2}^{*} \mathrm{Co}$, resulting in the appearance of characteristic absorbances for the $\mathrm{C}_{60}$ monoand di-anions between $800-1200 \mathrm{~nm}$ (Figure 5A). ${ }^{6}$ Similarly, sequential 1 $\mathrm{e}^{-}$reductions of $\mathbf{C}_{70} @$ Cage $^{4+}$ with $\mathrm{Cp}^{*}{ }_{2} \mathrm{Co}$ produces spectra that display absorbances consistent with those of $\mathrm{C}_{70^{-}}$ and $\mathrm{C}_{70}{ }^{2-}$ (Figure $5 \mathrm{~B}$ ). ${ }^{31}$ The Soret band and Q-peaks of Cage ${ }^{4+}$ remain unchanged in these spectra, confirming that the host is unreduced and that its electronic properties are not influenced much by hosting the fulleride anions.

\section{Conclusion}

In summary, a new covalently linked nanocage Cage $^{4+}$ has been synthesized on a gram scale using simple synthetic methods and inexpensive starting materials. This cage binds the fullerenes $\mathrm{C}_{60}$ and $\mathrm{C}_{70}$ with high affinities $\left(K_{\mathrm{a}}>10^{8} \mathrm{M}^{-1}\right)$ and displays excellent selectivity for extracting $\mathrm{C}_{70}$ from mixtures containing an excess of $\mathrm{C}_{60}$. Cage $^{4+}$ also binds the -1 and -2 states of the fullerenes,
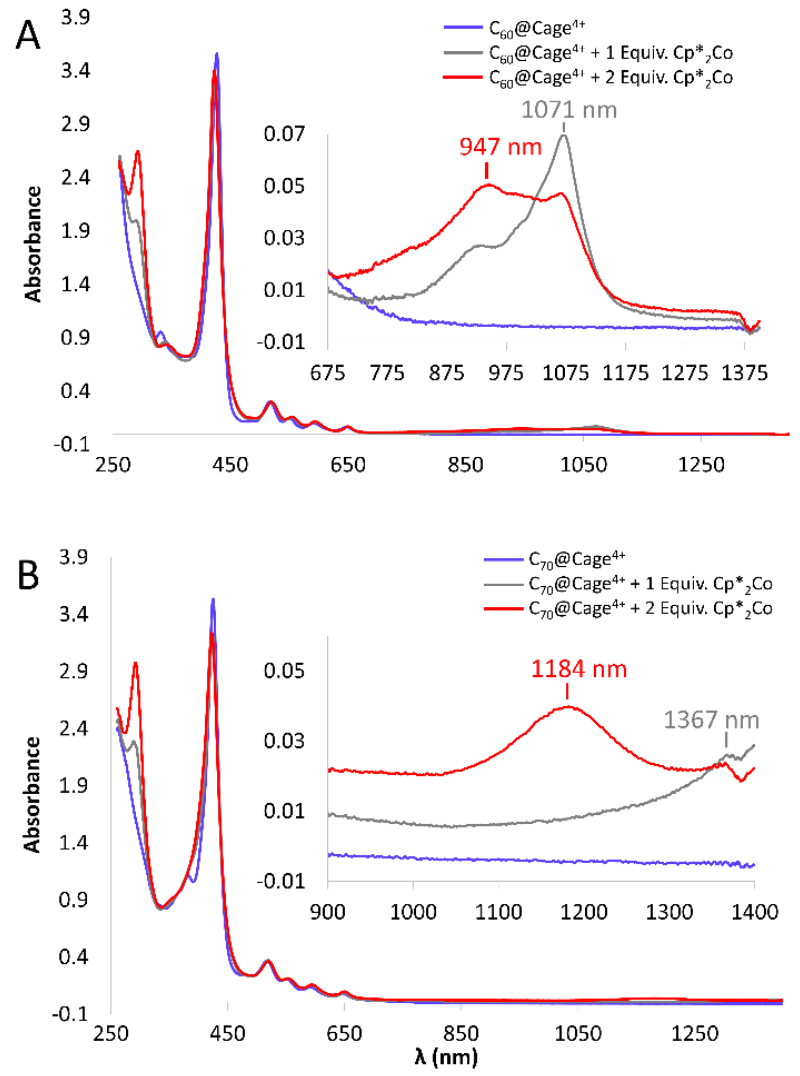

Figure 5: UV-vis-NIR spectra of (A) $\mathbf{C}_{60} @$ Cage $^{4+}$ and (B) $\mathbf{C}_{70} @$ Cage $^{4+}$ upon sequential 1 equiv additions of $\mathrm{Cp}^{*}{ }_{2} \mathrm{Co}$. Insets show magnified views of NIR absorbances that are characteristic of the anionic fullerenes. Spectra were recorded at $0.125 \mathrm{mM}$ concentrations of the host-guest complexes in DMF in a $1 \mathrm{~mm}$ pathlength cuvette.

and the different oxidation states of the host-guest complexes were characterized by several methods, including cyclic voltammetry and spectroscopic techniques (NMR and UV-VisNIR spectroscopies). These studies reveal that the electronic properties of the fullerenes are surprisingly unperturbed by encapsulation in $\mathrm{Cage}^{4+}$, in contrast to recent reports of fullerene guests in other cationic cages. . $^{4 a, c, d}$

These findings suggest that Cage $^{4+}$ may be a particularly useful host for separating and solubilizing fullerenes. Its performance is comparable to or better than that of many notable fullerene-binding hosts in terms of affinity for either fullerene and the ability to separate $\mathrm{C}_{70}$ from $\mathrm{C}_{60}$, while the low-cost scalable synthesis makes Cage $^{4+}$ much more promising for applications. Additionally, since solubilization of fullerenes by this host does not appear to substantially alter their electronic properties, $\mathbf{C}_{60} @$ Cage $^{4+}$ and $\mathbf{C}_{70} @$ Cage $^{4+}$ may be directly useful as solubilized fullerene derivatives that preserve the properties of the fullerene guests.

\section{Acknowledgements}

M.C.L. would like to thank the ACS Petroleum Research Fund (PRF grant \#61015-DNI3) and Rutgers, the State University of New Jersey for supporting this work. J.Z. would like to thank the support from the Department of Energy (grant no. DESC0020260). 


\section{References}

1. a.) R. Chakrabarty, P.S. Mukherjee, P.J. Stang, Chem. Rev. 2011, 111 (11), 6810-6918; b.) F.J. Rizzuto, L.K.S. von Krbek, J.R. Nitschke, Nat. Rev. Chem. 2019, 3 (4), 204-222; c.) E.G. Percástegui, V. Jancik, Coordination Chem. Rev. 2020, 407, 213165; d.) D. Canevet, E.M. Pérez, N. Martín, Angew. Chem., Int. Ed. Engl. 2011, 50 (40), 9248-9259; e.) T.Y. Kim, R.A.S. Vasdev, D. Preston,J.D. Crowley, Chem. Eur. J. 2018, 24, 14878-14890.

2. a.) C. García-Simón, M. Garcia-Borràs, L. Gómez, T. Parella, S. Osuna, J. Juanhuix, I. Imaz, D. Maspoch, M. Costas, X. Ribas, Nat. Commun. 2014, 5 (1), 5557; b.) Zhang, D.; T.K. Ronson, R. Lavendomme, J.R. Nitschke, J. Am. Chem. Soc. 2019, 141 (48), 18949-18953. c.) A.B. Grommet, J.B. Hoffman, E.G. Percástegui, J. Mosquera, D.J. Howe, J.L. Bolliger, J.R. Nitschke, J. Am. Chem. Soc. 2018, 140 (44), 14770-14776; d.) W. Brenner, T.K. Ronson, J.R. Nitschke, J. Am. Chem. Soc. 2017, 139 (1), 75-78; e.) E. Huerta, G.A. Metselaar, A. Fragoso, E. Santos, C. Bo, J. de Mendoza, Angew. Chem., Int. Ed. Engl. 2007, 46 (1-2), 202-205; f.) C. García-Simón, A. Monferrer, M. Garcia-Borràs, I. Imaz, D. Maspoch, M. Costas, X. Ribas, Chem. Commun. 2019, 55 (6), 798-801.

3. a.) M. Zhang, M.L. Saha, M. Wang, Z. Zhou, B Song, C. Lu, X. Yan, X. Li, F. Huang, S. Yin, P.J. Stang, J. Am. Chem. Soc. 2017, 139 (14), 5067-5074; b.) T. Kawase, K. Tanaka, Y. Seirai, N. Shiono, M. Oda, Angew. Chem., Int. Ed. Engl. 2003, 42 (45), 5597-5600.

4. a.) F.J. Rizzuto, D.M. Wood, T.K. Ronson, J.R. Nitschke, J. Am. Chem. Soc. 2017, 139 (32), 11008-11011; b.) R.L. Spicer, A.D. Stergiou, T.A. Young, F. Duarte, M.D. Symes, P.J. Lusby, J. Am. Chem. Soc. 2020, 142 (5), 2134-2139; c.) S. Hasegawa, S.L. Meichsner, J.J. Holstein, A. Baksi, M. Kasanmascheff, G.H. Clever, J. Am. Chem. Soc. 2021, 143 (26), 9718-9723; d.) K. Matsumoto, S. Kusaba, Y. Tanaka, Y. Sei, M. Akita, K. Aritani, M.A. Haga, M. Yoshizawa, Angew. Chem., Int. Ed. Engl. 2019, 58 (25), 8463-8467.

5 a.) M. Morimoto, S.M. Bierschenk, K.T. Xia, R.G. Bergman, K.N. Raymond, F.D. Toste, Nat. Catal. 2020, 3 (12), 969-984; b.) W.X.Gao, H.N. Zhang, G.X. Jin, Coord. Chem. Rev. 2019, 386, 6984.

6. C.A. Reed, R.D. Bolskar, Chem. Rev. 2000, 100 (3), 10751120 .

7. a.) W. Sun, Y. Wang, L. Ma, L.Zheng, W. Fang, X. Chen, H. Jiang, J. Org. Chem. 2018, 83 (23), 14667-14675; b.) M.J. Li, C.H. Huang, C.C. Lai, S.H. Chiu, Org. Lett. 2012, 14 (24), 6146-6149;

8. a.) X. Chang, S. Lin, G. Wang, C. Shang, Z. Wang, K. Liu, Y. Fang, P.J. Stang, J. Am. Chem. Soc. 2020, 142 (37), 15950-1596; b.) K. Suzuki, K. Takao, S. Sato, M. Fujita, J. Am. Chem. Soc. 2010, 132 (8), 2544-2545.

9. a.) E. Ubasart, O. Borodin, C. Fuertes-Espinosa, Y. Xu, C. García-Simón, L. Gómez, J. Juanhuix, F. Gándara, I. Imaz, D. Maspoch, M. von Delius, X. Ribas, Nat. Chem. 2021, 13 (5), 420-427; b.) V. Leonhardt, S. Fimmel, A. M. Krause, F. Beuerle, Chem. Sci. 2020, 11 (32), 8409-8415.

10. a.) H. Nobukuni, Y. Shimazaki, H. Uno, Y. Naruta, K. Ohkubo, T. Kojima, S. Fukuzumi, S. Seki, H. Sakai, T. Hasobe, F. Tani, Chem. Eur. J. 2010, 16 (38), 11611-11623; b.) Y. Shi, Y.; K. Cai, H. Xiao, Z. Liu, J. Zhou, D. Shen, Y. Qiu, Q.H. Guo, C. Stern, M.R. Wasielewski, F. Diederich, W.A. Goddard, J.F. Stoddart, J. Am. Chem. Soc. 2018, 140 (42), 13835-13842; c.) J. Song, N. Aratani, H. Shinokubo, A. Osuka, J. Am. Chem. Soc. 2010, 132 (46), 16356-16357, d.) C. Zhang, Q. Wang, H. Long, W. Zhang, W., J. Am. Chem. Soc. 2011, 133 (51), 20995-21001; e.) F. Hajjaj, K. Tashiro, H. Nikawa, N. Mizorogi, T. Akasaka, S. Nagase, K. Furukawa, T. Kato, T. Aida, J. Am. Chem. Soc. 2011, 133 (24), 9290-9292; f.) M. Schmittel, B. He,
P. Mal, Org. Lett. 2008, 10 (12), 2513-2516; g.) T. Nakamura, H. Ube, R. Miyake, M. Shionoya, J. Am. Chem. Soc. 2013, 135 (50), 1879018793; h.) W. Meng, B. Breiner, K. Rissanen, J.D. Thoburn, J.K. Clegg, J.R. Nitschke, Angew. Chem., Int. Ed. Engl. 2011, 50 (15), 3479-3483; i.) Y. Xu, S. Gsänger,M.B. Minameyer, I. Imaz, D. Maspoch, O. Shyshov, F. Schwer, X. Ribas, T. Drewello, B. Meyer, M. von Delius, J. Am. Chem. Soc. 2019, 141 (46), 18500-18507; j.) A.R. Mulholland, C.P. Woodward, S.J. Langford, Chem. Commun. 2011, 47 (5), 1494-1496; k.) A.L. Kieran, S.I. Pascu, T. Jarrosson, J.K.M. Sanders, Chem. Commun. 2005, (10), 1276-1278; I.) D.M. Wood, W. Meng, T.K. Ronson, A. Stefankiewicz, J.K.M. Sanders, J.R. Nitschke, Angew. Chem., Int. Ed. Engl. 2015, 54 (13), 3988-3992; m.) Z. Lu, T.K. Ronson, J.R. Nitschke, Chem. Sci. 2020, 11 (4), 10971101.

11. a.) T.A. Barendt, W.K. Myers, S.P. Cornes, M.A. Lebedeva, K. Porfyrakis, I. Marques, V. Félix, P. De Beer, Journal of the American Chemical Society 2020, 142 (1), 349-364; b.) K. Mahata, P.D. Frischmann, F. Würthner, J. Am. Chem. Soc. 2013, 135 (41), 1565615661 ; c) T.K. Ronson, T. K.; A.B. League, L. Gagliardi, C.J. Cramer, J.R. Nitschke, J. Am. Chem. Soc. 2014, 136 (44), 15615-15624.

12. a.) V. Martínez-Agramunt, T. Eder, H. Darmandeh, G. GuisadoBarrios, E. Peris, Angew. Chem., Int. Ed. Engl. 2019, 58 (17), 56825686; b.) V. Martínez-Agramunt, D.G. Gusev, E. Peris, Chem. Eur. J. 2018, 24 (55), 14802-14807.

13. a.) N. Kishi, M. Akita, M. Kamiya, S. Hayashi, H.F. Hsu, M. Yoshizawa, J. Am. Chem. Soc. 2013, 135 (35), 12976-12979; b.) N. Kishi, Z. Li, K. Yoza, M. Akita, M. Yoshizawa, J. Am. Chem. Soc 2011, 133 (30), 11438-11441; c.) T.K. Ronson, B.S. Pilgrim, J.R. Nitschke, J. Am. Chem. Soc. 2016, 138 (33), 10417-10420; d.) M. Yamashina, T. Yuki, Y. Sei, Y.; Akita, M. Yoshizawa, Chem. Eur. J. 2015, 21 (11), 4200-4204; e.) D. Canevet, M. Gallego, H. Isla, A. de Juan, E.M. Pérez, N. Martín, J. Am. Chem. Soc. 2011, 133 (9), 3184 3190; f.) G. Bastien, P.I. Dron, M. Vincent, D. Canevet, M. Allain, S. Goeb, M. Sallé, Org. Lett. 2016, 18 (22), 5856-5859.

14. a.) J.Q. Wang, Y. Han, C.F. Chen, Chem. Commun. 2021, 57 (33), 3987-3990; b.) M. Samanta, A. Rananaware, D.N. Nadimetla, S. A. Rahaman, M. Saha, R.W. Jadhav, S.V. Bhosale, S. Bandyopadhyay, Sci. Rep. 2019, 9 (1), 9670; c.) C. Coluccini, D. Dondi, M. Caricato, A. Taglietti, M. Boiocchi, D. Pasini, Org. Biomol. Chem. 2010, 8 (7), 1640-1649; d.) K.A. Nielsen, W.S. Cho, G.H. Sarova, B.M. Petersen, A.D. Bond, J. Becher, F. Jensen, D.M. Guldi, J.L. Sessler, J.O. Jeppesen, Angew. Chem., Int. Ed. Engl. 2006, 45 (41), 6848-6853; e.) T. Matsuno, S. Sato, R. lizuka, H. Isobe, Chem. Sci. 2015, 6 (2), 909-916; f.) A. Sygula, F.R. Fronczek, R. Sygula, P.W. Rabideau, M.M. Olmstead, J. Am. Chem. Soc. 2007, 129 (13), 3842-3843; g.) B. Chen, J.J. Holstein, S. Horiuchi, W.G. Hiller, G.H. Clever, J. Am. Chem. Soc. 2019, 141 (22), 8907-8913; h.) A. Ikeda, H. Udzu, M. Yoshimura, M.; S. Shinkai, Tetrahedron 2000, 56 (13), 1825-1832; i.) M. Zhang, H. Xu, M. Wang, M.L. Saha, Z. Zhou, X. Yan, H. Wang, X. Li, F. Huang, N. She, P.J. Stang, Inorg. Chem. 2017, 56 (20), 12498-12504; j.) S.I. Kawano, T. Fukushima, K. Tanaka, Angew. Chem. Int. Ed. Engl. 2018, 57 (45), 14827-14831; k.) X. Zhang, H. Shi, G. Zhuang, S. Wang, J. Wang, S. Yang, X. Shao, P. Du, Int. Ed. Engl. 2021, 60 (21), 17368-17372; I.) Y. Ni, F. Gordillo-Gamez, M.P. Alvarez, Z. Nan, Z. Li, S. Wu, Y. Han, J. Casado, J. Wu, J. Am. Chem. Soc. 2020, 142(29), 12730-12742; m.) P.C. Purba, M. Maity, S. Bhattacharyya, P.S. Mukerjee, Angew. Chem., Int. Ed. Engl. 2021, 60 (25), 14109-14116; n.) G. Zango, M. Krug, S. Krishna, V. Marinas, T. Clark, M.V. Martinez-Diaz, D.M. Guildi, T. Torres, Chem. Sci. 2020, 11, 3448-3459.

15. For fullerene receptors utilizing precious metals as linking agents for aromatic walls, see references $2 a, 7 a, 8 b, 10 j, 13 b, 13 d$, $14 \mathrm{~b}$, and $14 \mathrm{j}$. 
16. For fullerene receptors formed using covalent linkages, see references $10 \mathrm{~b}, 10 \mathrm{~d}, 10 \mathrm{i}, 10 \mathrm{k}, 14 \mathrm{e}, 14 \mathrm{f}, 14 \mathrm{k}, 14 \mathrm{l}$ and $14 \mathrm{n}$.

17. For fullerene receptors requiring numerous synthetic steps, see references $4 \mathrm{~d}, 7 \mathrm{a}, 10 \mathrm{a}, 10 \mathrm{~d}, 10 \mathrm{e}, 10 \mathrm{f}, 10 \mathrm{i}, 10 \mathrm{j}, 14 \mathrm{f}, 14 \mathrm{j}$, and $14 \mathrm{k}$.

18. We define a $3 D$ receptor as having a well-defined three dimensional pore (see references $2 a, 2 f, 4 a, 7 a, 8 a, 8 b, 9 b, 10 a, 10 b$, 10c, 10d, 10e, 10f, 10g, 10h, 10i, 10j, 10k, 10l, 10m, 11a, 11b, 11c, $12 \mathrm{a}, 12 \mathrm{~b}, 13 \mathrm{a}, 13 \mathrm{~b}, 13 \mathrm{c}, 14 \mathrm{c}, 14 \mathrm{~h}, 14 \mathrm{i}, 14 \mathrm{j}, 14 \mathrm{l}, 14 \mathrm{~m}$, and 14n). This definition includes all nanocage structures as well as macrocycles with large aromatic surfaces that define a 3D volume between them, but excludes excludes most molecular tweezers, macrocycles, and linear "wrap-around" hosts that typically show lower association constants for binding fullerenes. Even among these latter receptors, only one has been prepared on a scale of $>1 \mathrm{~g}$ (see reference 11c).

19. K.N. Semenov, N.A. Charykov, V.A. Keskinov, A.K. Piartman, A.A. Blokhin, A. A. Kopyrin, J. Chem. Eng. Data. 2010, 55 (1), 13-36.

20. Crystalization from MeCN was unsuccessful using a variety of antisolvents (isopropyl ether, diethyl ether, tert-butyl methyl ether, dichloromethane, and hexanes) regardless of the conditions (room temperature or reduced temperatures) or technique (slow diffusion, layering, slow evaporation). Similar attempts at crystallization from DMF were also unsuccessful at growing crystals suitable for singlecrystal XRD analysis, though poorly diffracting crystals of Cage $4 \mathrm{PF}_{6}$ were obtained by room temperature vapor diffusion of $\mathrm{Et}_{2} \mathrm{O}$ or ${ }^{2} \mathrm{Pr}_{2} \mathrm{O}$ into DMF solutions of Cage•4PF 6 .

21. L. Avram, Y. Cohen, Chem. Soc. Rev. 2015, 44 (2), 586-602.

22. This distance is the sum of the van der Waals radii of two carbon atoms added to the longest internuclear $\mathrm{C}---\mathrm{C}$ distance in computationally optimized structure of Cage $^{4+}$.

23. a.) C. Vicent, V. Martinez-Agramunt, V. Ghandi, C. LarribaAndaluz, D.G. Gusev. E. Peris, Angew. Chem., Int. Ed. Engl. 2021, 60 (28), 15412-15417; b.) E. Kalenius, M. Groessl, K. Rissanen, Nat. Rev. Chem. 2019, 3, 4-14; c.) L. Polewski, A. Springer, K. Pagel, C.A. Schalley, Acc. Chem. Res. 2021, 54 (10), 2445-2456.

24. We also attempted to characterize Cage $^{4+}$ and its host-guest complexes by differential pulse voltammetry, but reliable DPV measurments could not be obtained, possibly due to adhesion of Cage $^{4+}$ to the electrode.

25. D. Dubois, G. Moninot, W. Kutner, M.T. Jones, K.M. Kadish, J. Phys. Chem. 1992, 96, 7137-7145.

26. Reduciton potentials of $\mathrm{C}_{70}$ were measured in DMF $(0.1 \mathrm{M}$ $\mathrm{TBAPF}_{6}$ ) following the technique described in reference 77.

27. The first reduction potential of $\mathbf{C}_{60} @ \mathbf{C a g e}^{4+}$ was also evaluated in DMF by chemical reduction with dialkyl- and diaryl- viologen radical cations, providing results that are consistent with the first reduction potential of this host-guest complex measured by CV. See Figures S53, S54, S63, and S64.

28. L. Echegoyen, L. Echegoyen, Acc. Chem. Res. 1998 (31), 592601

29. R.C. Haddon, R.E. Palmer, H.W. Kroto, P.A. Sermon, Philos. Trans. Royal Soc. 1993, 343(1667), 53-62.

30. K.G. Dutton, D.A. Rothschild, D.B. Pastore, T.J. Emge, M.C. Lipke, Inorg. Chem. 2020, 59 (17), 12616-12624.

31. D.R. Lawson, D.L. Feldhiem, C.A. Foss, P.K. Dorhout, C.M. Elliott, C.R. Martin, B. Parkinson, 1992, 96 (18), 7175-7177. 